\title{
The structure of a mutant $\mathrm{H}-2$ gene suggests that the generation of polymorphism in $\mathrm{H}-2$ genes may occur by gene conversion-like events
}

\author{
E. H. Weiss ${ }^{* \dagger}$, A. Mellor ${ }^{* \dagger}$ L. Golden ${ }^{* \dagger}$, K. Fahrner ${ }^{\dagger}$, E. Simpson ${ }^{\ddagger}$, \\ J. Hurst" \& R. A. Flavell ${ }^{\dagger}$
}

\author{
* Laboratory of Gene Structure and Expression, National Institute for Medical Research, Mill Hill, London NW7 1AA, UK \\ † Biogen Inc., 241 Binney Street, Cambridge, Massachusetts 02142, USA \\ $\ddagger$ Clinical Research Centre, Watford Road, Harrow, Middlesex HA1 3UJ, UK
}

\begin{abstract}
We have cloned a mutant allele of the $\mathrm{H}-2 \mathrm{~K}^{\mathrm{b}}$ gene known as $\mathrm{H}-2 \mathrm{~K}^{\mathrm{bml}}$. DNA sequence analysis of this gene shows that it is the result of an intergenic exchange of DNA (gene conversion) which results in the conversion of a short internal segment of the $\mathrm{H}-2 \mathrm{~K}^{\mathrm{b}}$ to the corresponding sequence of another $\mathrm{H}-2$ gene. We suggest that this type of gene conversion is widespread in H-2 genes and that it is a major force in the generation of polymorphism in $\mathrm{H}-2$ genes.
\end{abstract}

THE major histocompatibility complex (MHC) has an important role in the regulation of the immune response in vertebrates. The so-called class I MHC proteins are the classical transplantation antigens: in mouse $\mathrm{H}-2 \mathrm{~K}, \mathrm{D}$ and $\mathrm{L}$, and in man HLA-A, $\mathrm{B}$ and $\mathrm{C}$. These proteins appear to function by presenting foreign antigens such as viral proteins to cytotoxic $T$ cells of the immune system and are found on virtually all cell types. The genes for the murine class I antigens are localized on chromosome 17; Fig. 1 is a schematic genetic map of the locus; it shows the class II (Ir) genes sandwiched between $H-2 K$ and $H-2 D$. The $Q a$ and $T l a$ genes are localized telomeric to the $H-2 D$ gene and encode class I-related antigens which are expressed on certain classes of lymphoid cell. Both the class I $\mathrm{H}-2 \mathrm{~K}, \mathrm{D}, \mathrm{L}$ antigens and the $\mathrm{Qa}$ and Tla antigens are integral membrane proteins of 40-45,000 molecular weight associated with $\beta_{2}$-microglobulin, a protein of 12,000 molecular weight, not encoded in the MHC.

Molecular cloning of the $\mathrm{H}-2$ genes has shown that there are a large number of $\mathrm{H}-2$ related DNA sequences in the mouse and that, surprisingly, the majority are located in the $Q a 2.3$ and Tla regions ${ }^{1-4}$. These studies also establish the high degree of homology between the classical class I genes and genes in the $Q a$ and Tla regions.

An intriguing property of the $\mathrm{H}-2$ and HLA antigens is their extreme polymorphism. Allelic gene products from different inbred mouse strains differ extensively in amino acid sequence and hence in serological properties. About 50 different alleles at each of the $H-2 K$ and $H-2 D$ loci have been observed (see ref. 5). Most significantly, a given allele of, say, the $\boldsymbol{H}-2 \mathrm{~K}$ gene is commonly no more similar to another allele than it is to a given non-allelic $\boldsymbol{H}-2 D$ gene. This unusual genetic phenomenon has a precedent. Thus, Slightom et al. ${ }^{6}$ showed that a human ${ }^{A} \gamma$-globin gene was more similar in DNA sequence to its linked ${ }^{\circ} \gamma$-globin gene than it was to the allelic ${ }^{\mathrm{A}} \gamma$-globin gene found on the other homologous chromosome. They suggested that this resulted from a intergenic exchange during recombination (called here a gene conversion event) between the two linked ${ }^{A} \gamma$ - and ${ }^{G} \gamma$-globin genes which caused the A $\gamma$-globin sequence to be corrected against (converted to) the linked ${ }^{G} \gamma$-globin gene ${ }^{6}$. These and other observations led us to suggest that similar gene conversion events could be responsible for the introduction of new sequences in a given $\mathrm{H}-2$ gene and hence for the generation of a high number of polymorphic alleles at the $H-2$ loci in the mouse population; donor nonallelic $\mathrm{H-2}, \mathrm{Qa}$ or $\mathrm{Tla}$ genes or pseudogenes could be the source of new information for incorporation at the $\mathrm{H}-2 \mathrm{loci}^{7}$. Others have made similar suggestions ${ }^{8,9}$.
Ideally, to establish the mechanism underlying such a genetic event, it is desirable to have the DNA sequence of donor and recipient genes before and after the event. This is made possible by the fact that spontaneous mutants from inbred mouse strains exist which have altered $\mathrm{H}-2$ molecules and hence carry new polymorphic alleles. Therefore, if a gene conversion event has occurred both donor and recipient genes are available in the non-mutant strain so three of the four pieces of the puzzle can be determined.

We have previously cloned and sequenced the $H-2 K^{b}$ gene of the B10 mouse ${ }^{10}$. We have therefore chosen to clone and sequence the gene encoding a mutant form of this gene, $H-2 K^{b m l}$. The comparison of these sequences shows that a total of seven nucleotide changes have occurred in the $H-2 K^{b m l}$ gene which cause three amino acid substitutions. These nucleotide changes are clustered in a 13-nucleotide region of the $\mathrm{H}-2 \mathrm{~K}$ gene. We suggest that these mutations have been introduced into the $H-2 K^{b}$ gene by a gene conversion-like event and that these events have a major role in the generation of polymorphism in $\mathrm{H}-2$ genes.

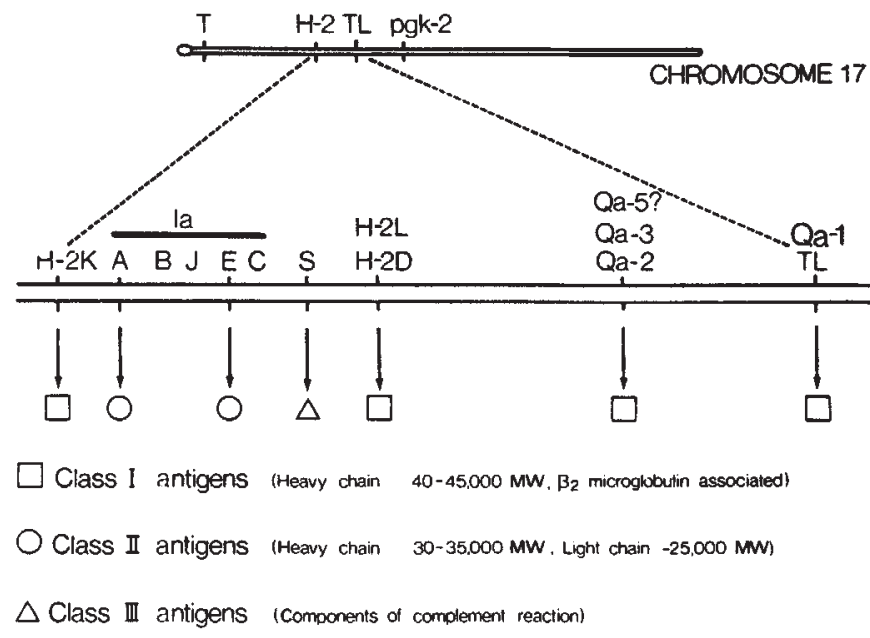

Fig. 1 Genetic map of the murine $H-2$ and associated genetic loci. The top line shows a diagram of chromosome 17 with the centromere on the left. The bottom line shows an expanded diagram of the regions between the $H-2 K$ locus on the left and the $T L$ locus on the right. H-2 class 1 molecules $(\square)$ are expressed from at least four separate genetic loci as shown by the arrows below the line. 
Fig. 2 A restriction enzyme map of the region containing the $H-2 K^{b}$ and $H-2 K^{b m l}$ gene; with this enzyme the two regions are indistinguishable. The middle line shows the extent of the cloned region with the KpnI (K) restriction sites. Class 1 genes (A and B) are shown with arrows indicating the direction of transcription $5^{\prime} \rightarrow 3^{\prime}$. The hatched boxes indicate the localization of the 5 'flanking $B a m H I$ fragment used for screening. Above the restriction map is shown the extent of the overlapping cosmids from the B10 library (H) and below are the overlapping cosmids from the B6 bml library (bml).
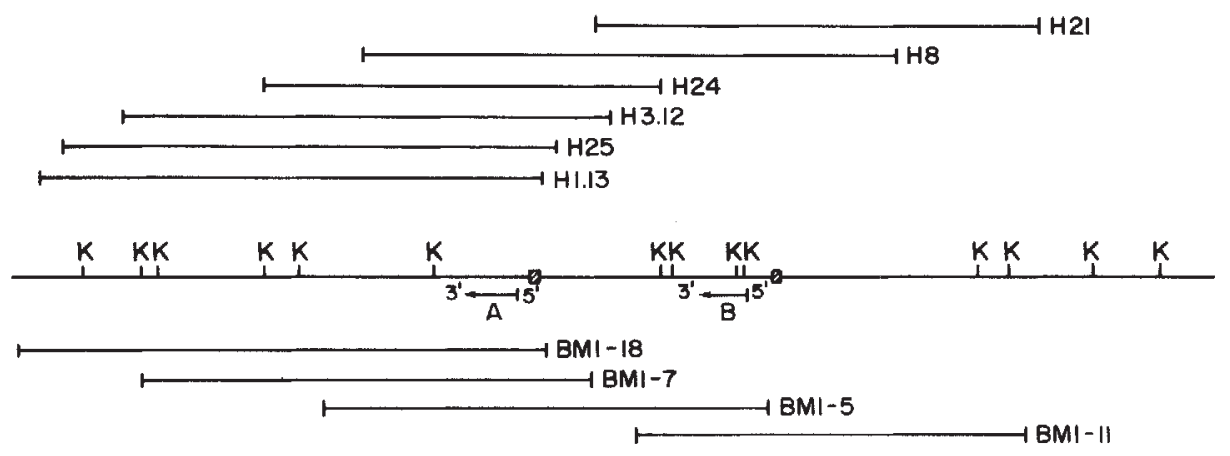

$10 \mathrm{~kb}$ $\mathrm{BMI}-2$

\section{Isolation of the mutant $H-2 K$ region}

We have previously cloned the $H-2 K^{b}$ region from a cosmid library prepared from the B10 mouse ${ }^{4}$. We used the same general strategy to isolate this region from the $\mathrm{B} 6^{\mathrm{bml}}$ mutant. A cosmid library was prepared using procedures developed in this laboratory ${ }^{11,12}$ and screened with a probe from the $5^{\prime}$ flanking sequences of the $H-2 K^{b}$ gene (see ref. 4). This probe detects about six DNA segments linked to $H-2$ related genes from the $H-2 K$ and $Q a 2,3$ regions. The clones obtained were then examined by restriction enzyme digestion and Southern blot hybridization to detect the $H-2 K^{b m l}$ locus. Five overlapping clones at the $H-2 K$ locus were obtained and restriction maps were determined. The general organization of this region is identical to that reported by us previously for the $H-2 K^{b}$ region ${ }^{4}$; two linked genes are seen as shown on the map of Fig. 2. That the bml mutation indeed resides within the $H-2 K$ gene previously identified ${ }^{4}$ was shown by subcloning this gene and transforming mouse L cells. The L-cell transformants were then used as target cells for allogeneic cytotoxic $T$ cells derived from the $H-2^{b}$ mouse (B10) and directed against spleen cells from the bml mouse (Fig. 3). These transformed cells are killed by cytoxic $\mathrm{T}$ cells specific for bml but are not killed by cytotoxic $\mathrm{T}$ cells directed against the $\mathrm{H}-2 \mathrm{~K}^{\mathrm{b}}$ determinant. This result excludes the alternative explanation that the $H-2 K^{b}$ gene has become silent and that the $\mathrm{H}-2^{\mathrm{bml}}$ antigen is expressed from another gene in the genome.

Comparative fine mapping studies were also performed on the subcloned $H-2 K^{b}$ and $H-2 K^{b m l}$ genes (Fig. 4). Two differences were seen in exon 3 which encodes the second domain of the $\mathrm{H}-2$ molecule. First, a HinfI site is present in $H-2 K^{b}$ but absent in $H-2 K^{b m l}$; this site is present at the codons for amino acid residues 155 and 156 which are altered from Arg-Leu in $\mathrm{K}^{\mathrm{b}}$ to Tyr-Tyr in $\mathrm{K}^{\mathrm{bml}}$, therefore this change is expected. In addition, a Pst $\mathrm{I}$ site has been gained by the $H-2 K^{b m l}$ gene just $5^{\prime}$ of the Hinfl site. These observations suggest that multiple nucleotide differences must occur between these two genes.

\section{The DNA sequence of the $H-2 K^{b m l}$ gene}

We have therefore determined the DNA sequence of exons 1 to 6 of the $H-2 K^{b m l}$ gene and segments of their flanking introns using the Maxam-Gilbert procedure and the strategy outlined in Fig. 4 legend. In total only eight nucleotide differences are evident. A single nucleotide difference exists in intron 1 where $K^{b}$ has a T and $K^{b m l}$ has an A at the residue 116 nucleotides from the $5^{\prime}$ end of the intron. This may be a polymorphic difference between the $H-2 K^{b}$ gene from these two closely related mouse strains (the $H-2 K^{b}$ gene is from $\mathrm{B} 10$ and the $K^{b m l}$ gene from $\mathrm{B} 6$ ). The remaining seven differences are clustered in a short region of 13 nucleotides of exon 3 ; two changes are present in the codon for amino acid 152 which cause an amino acid substitution from Glu (GAA) to Ala (GCT) and five changes at the codon for amino acids 155 and 156

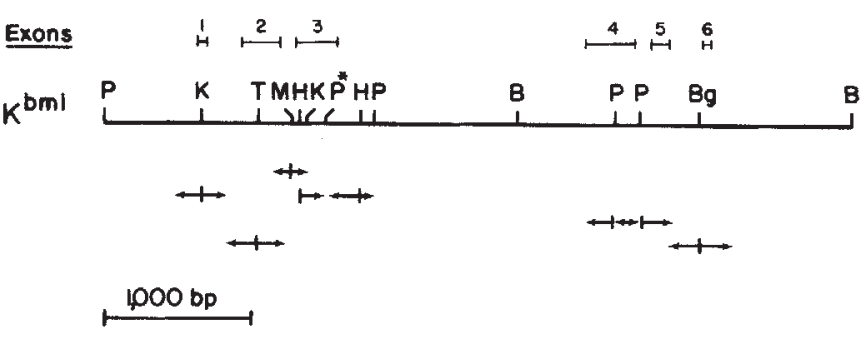

Fig. 3 Fine restriction map of the $H-2 K^{b m l}$ gene and sequence strategy. The middle line shows a fine restriction map of the $H-2 K^{b m l}$ gene. B, BamHI; Bg, BglII; H, HinfI; K, KpnI; M, MspI; P, PstI; T, TaqI. Above the restriction map is shown the position of exon 1 (leader) and exons 2 (first domain), 3 (second domain), 4 (third domain), 5 (transmembrane part), 6 (first cytoplasmic part). The straight arrows below show the direction and length of the fragments sequenced with the Maxam and Gilbert procedure. *An additional Pst I site in the $H-2 K^{b m l}$ gene, not found in the $H-2 K^{b}$ gene.

causing Arg 155(AGA) $\rightarrow$ Tyr 155(TAT) and Leu 156(CTC) $\rightarrow$ Tyr 156(TAC). The changes at residues 155 and 156 agree with the published data from the structural analysis of the protein but the change at residue 152 must have been missed in that study ${ }^{13}$. Our data show that these changes have occurred in the $H-2 K^{b}$ gene. We consider that a gene conversion event is the most likely cause for this phenomenon in which case there must be a donor gene which contains this novel nucleotide sequence. There are many candidates for such a donor gene in the mouse genome because estimates of the number of class I-related genes in the mouse genome range between 15 to 30 (refs 3,14 ). Of the reported $H-2$ class I sequences; $H-2 K^{d}$ (S. Kvist, personal communication), $H-2 D^{d}$ (ref. 15), $H-2 L^{d}$ (refs 9, 16), H-2D bef. 17), clone 27.1 (ref. 1) and the $H-2$-like gene closely linked to $H-2 K^{b}$ (Fig. 5), $H-2 L^{d}$ is the only gene which contains the amino acids found in the bml sequence in this region. It is, in fact, possible that the $H-2 L^{d}$ gene was the donor gene as the bml mutation was first detected in a heterozygous $(\mathrm{B} 6 \times \mathrm{BALB} / \mathrm{c}) \mathrm{F}_{1}$ mouse ${ }^{13,18}$. In this case, the extent of the gene conversion event can be predicted (Fig. 5 ) and must be from $13-51$ bases. If the $H-2 L^{d}$ gene was the donor gene, however, the gene conversion event must have taken place in the zygote. It is also possible that the donor gene was another class I gene or pseudogene in the B6 or BALB/c genome and which also contains the same nucleotide sequence in the region from residues $152-156$. Further experiments will be required to exclude this. In addition, it is not formally excluded that the seven nucleotide changes seen here are independent point mutations, or a hot spot of nucleotide substitutions caused by a conventional base-substitution mechanism. We consider these unlikely; and the fact that the $H-2 L^{d}$ sequence in this area is identical supports this point of view. 


\begin{abstract}
Fig. 4 Comparison of the DNA and protein sequence of the $H-2 K^{b}$ gene, $H-2 K^{b m l}$ gene, $H-2 L^{d}$ gene, ${ }^{g, 17}$ and the ' $A$ ' gene of gene region I (refs 4,14 ) (see Fig. 2) starting from amino acid 145 to 168 . The recognition sequences for the enzymes PstI and HinfI are underlined. Only the nucleotides and amino acid differences from $H-2 K^{b}$ are shown in the $H-2^{b m l}, H-2 L^{d}$ and

$$
\text { 'A' gene. }
$$
\end{abstract}

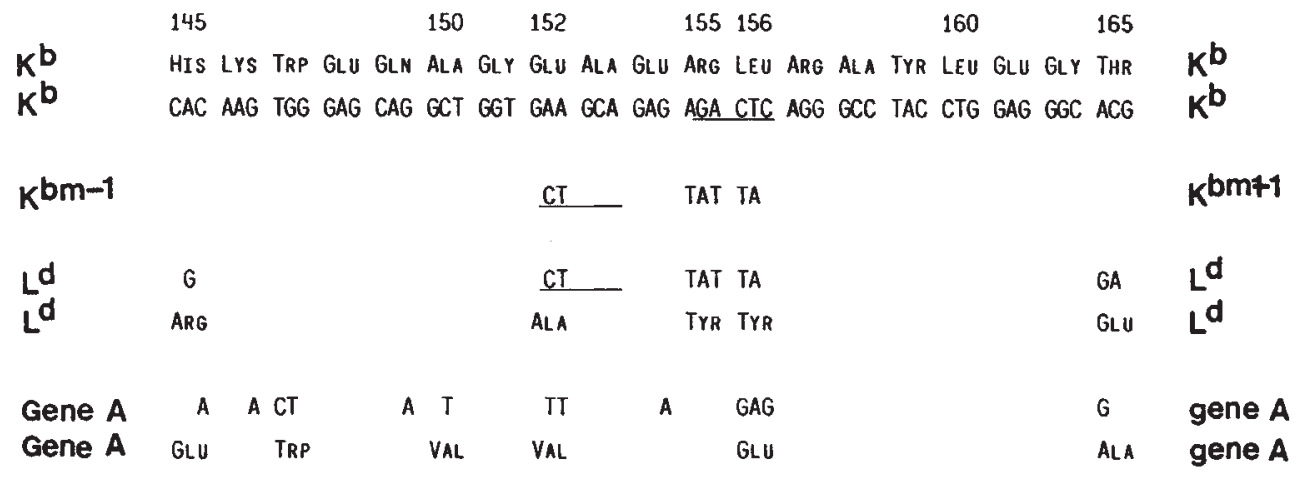

\section{Generation of polymorphism in the MHC}

Non-allelic gene conversion is a likely explanation for the origin of the bml mutant. The limited amino acid sequence data available for additional $H-2$ mutants suggest that this may turn out to be a general phenomenon. $\mathrm{H}-2 \mathrm{~K}^{\mathrm{bm} 6}$ and $\mathrm{H}-2 \mathrm{~K}^{\mathrm{bmg}}$ has two amino acid substitutions, namely Tyr $116 \rightarrow$ Phe and Cys $121 \rightarrow$ Arg. This requires a minimum of two nucleotide substitutions and interestingly Phe 116 and Arg 121 are already found in $H-2 D^{b}$. Thus, a conversion using $H-2 D^{b}$ as the donor gene might be the source of the new information in $H-2 K^{\text {bmo }}$.

Likewise bm5 and bm6 have a single substitution at Tyr $116 \rightarrow$ Phe 116 ; again Phe 116 is present in $H-2 D^{b}$. A second argument supporting gene conversion as the origin of many H-2 mutants is the fact that the same mutation has been isolated in different experiments. This would be expected for a gene conversion event and would be unlikely for conventional base substitutions unless there would be a strong selection for these particular amino acid changes. It is striking that the seven base changes are clustered in a very short region of DNA in the bml mutant gene. Furthermore, the polypeptide sequences in the other mutants cited above suggest that short conversion events will be the rule rather than the exception.

We consider it likely that gene conversion may turn out to be the major force in the generation of new alleles of $\mathrm{H}-2$ genes. The mutants seen above are almost certainly part of the same genetic phenomenon that is responsible for the production of new $\mathrm{H}-2$ alleles in the wild mouse. The gene conversion discussed above must have occurred between non-allelic genes and conceivably between two different haplotypes and hence different chromosomes in a heterozygous mouse. Furthermore, we should expect that genetic exchanges between alleles will occur and these can potentiate the transmission of new information from a 'converted' allele to other alleles of the same gene within the mouse population. The fact that the $H-2 K$ and $H-2 D$ genes show little ' $K$-ness' and ' $D$-ness', at least in certain haplotypes, suggests that non-allelic genetic exchanges must have a profound role in the generation of polymorphism. It is interesting that while the classical $H-2 K$ and $D$ genes show extensive polymorphism, there are only few alleles of expressed $Q a$ and $T L$ genes. If the $Q a$ and $T L$ genes participate in gene conversion events, then they do this either only as donors, or alternatively there is a strong selection eliminating the changes that have been introduced in the $Q a$ and $T L$ genes.

Is gene conversion in $\mathrm{H}-2$ genes more frequent than in other genes and, if so, is there anything unique about the structure of $\mathrm{H}-2$ genes to promote this? It is not possible to say whether the frequency in $\mathrm{H}-2$ genes is higher than, for example, in globin genes. Certainly polymorphism is rare in globin genes. We have sequenced four $\beta$-globin genes and found them to be identical in DNA sequence even in intron sequences which have little or no selection on their primary DNA sequence ${ }^{19,20}$. Polymorphic forms have been detected but again the number of these is extremely limited. Gene conversion events have occurred in the globin (and immunoglobulin) gene families but these seem to be rare and should be considered over evolutionary time scales (see, for example, ref. 6). As far as unique structures in $\mathrm{H}-2$ genes are concerned, we are struck by the

high $\mathrm{G}+\mathrm{C}$ content of $\mathrm{H}-2$ introns (greater than $90 \%$ near exons) compared with, say, globin genes where the introns are in fact A $+\mathrm{T}$ rich. Slightom et al. ${ }^{6}$ noted that the gene conversion event in the human $\gamma$-globin genes was associated with the presence of a short (about 40 nucleotides) CG : TG heteropolymer; the $H-2$ intron sequences have some similarities with this

Table 1 Lysis of $\mathrm{L}$ cells transformed with cloned $b$ and $b m l \mathrm{H}-2 \mathrm{~K}$ genes

\begin{tabular}{|c|c|c|}
\hline \multirow[b]{2}{*}{$\begin{array}{l}\text { Target } \\
\text { cells }\end{array}$} & \multicolumn{2}{|c|}{$\begin{array}{l}\text { \% Specific lysis } \\
\text { Cytotoxic T cells }\end{array}$} \\
\hline & $\begin{array}{c}\text { anti-K }^{\mathrm{b}} \\
\text { (bml anti-B10) }\end{array}$ & $\begin{array}{c}\text { anti-bml } \\
(\mathrm{CBA} \times \mathrm{B} 10) \text { anti-bml }\end{array}$ \\
\hline $\begin{array}{l}\text { B10.A(5R) }\left(\mathbf{K}^{\mathbf{b}}\right) \\
\text { bm1 }\left(\mathbf{K}^{\text {bml }}\right) \\
\text { LD-1 }\end{array}$ & $\begin{array}{c}28^{*} \\
-6 \\
5\end{array}$ & $\begin{array}{l}5 \\
65^{*} \\
-6\end{array}$ \\
\hline \multicolumn{3}{|l|}{ Expt 1} \\
\hline LD $1 / \mathrm{Bm} 5 / \mathrm{G}$ & 6 & $20^{*}$ \\
\hline $\begin{array}{l}\mathrm{LD} 1 / \mathrm{Bm} 5 / \mathrm{H} \\
\mathrm{LD} 1 / \mathrm{Bm} 7 / \mathrm{G}\end{array}$ & -3 & $\begin{array}{c}28^{*} \\
0\end{array}$ \\
\hline $\mathrm{LD} 1 / \mathrm{Bm} 11 / \mathrm{G}$ & & $19^{*}$ \\
\hline $\begin{array}{l}\mathrm{LD} 1 / \mathrm{BM} 18 / \mathrm{G} \\
\mathrm{LD} 1 / \mathrm{Bm} 21 / \mathrm{G}\end{array}$ & $1 F$ & $\begin{array}{l}-3 \\
32^{*}\end{array}$ \\
\hline LH8-2 & $21^{*}$ & -4 \\
\hline \multicolumn{3}{|l|}{ Expt 2} \\
\hline B10 & $56^{*}$ & 8 \\
\hline bm1 & 6 & 77* \\
\hline $\mathrm{LD} 1 / \mathrm{Bm} 7 / \mathrm{G}$ & 4 & 1 \\
\hline $\mathrm{LD} 1 / \mathrm{Bm} 11 / \mathrm{G}$ & 3 & $13^{*}$ \\
\hline $\mathrm{LD} 1 / \mathrm{Bm} 18 / \mathrm{G}$ & 3 & 2 \\
\hline $\mathrm{LD} 1 / \mathrm{Bm} 21 / \mathrm{G}$ & 3 & $24 *$ \\
\hline LH8-2 & $8^{*}$ & 1 \\
\hline
\end{tabular}

$1-2 \times 10^{6}$ target cells were labelled with $100 \mu \mathrm{Ci}{ }^{51} \mathrm{Cr}$-labelled sodium chromate for $1 \mathrm{~h}$ then washed twice. $1 \times 10^{4}$ labelled target cells in 100- $\mu$ l volumes were placed in round-bottomed wells of microtitre plates. For cytotoxic T-cell lysis (CML) killer cells generated in 5-day mixed lymphocyte cultures of the strain combinations designated were added in $100 \mu l$ to give attacker:target $(\mathrm{A}: \mathrm{T})$ ratios starting at $50: 1$ and thereafter at doubling dilutions of attackers giving four different $A: T$ ratios in all. Three triplicate wells of each $A: T$ ratio were set up. After $4 \mathrm{~h}$ incubation at $37^{\circ} \mathrm{C}$ in a $5 \% \mathrm{CO}_{2}$ humidified atmosphere the plates were spun and $100 \mu \mathrm{l}$ of the supernatant from each well was collected and counted for released $\gamma$ counts. The per cent specific lysis was calculated according to the formula

$$
E-C / M-C \times 100 \%
$$

where $E$ is c.p.m. for target cells incubated with killer cells, $C$ is c.p.m. from target cells incubated with medium alone and $M$ is c.p.m. from target cell lysis with Triton. The per cent specific lysis shown is for an A:T ratio of 20:1 and the value is taken from a 12-point regression analysis of the data obtained in the titration described above. LD1, control $L$ cells. LD1 cells were transformed with cosmid DNA (BM1-5, BM1-7, BM1-11, BM1-18 and BM1-21) using the $\mathrm{CaPO}_{4}$ mediated DNA transfer technique ${ }^{21}$. Population of transformed cells ( $\mathrm{Bm} 5, \mathrm{Bm} 7$, $\mathrm{Bm} 11, \mathrm{Bm} 18$ and $\mathrm{Bm} 21$ respectively) were selected using G418 (G) or hypoxanthine-aminopterin-thymidine $(\mathrm{H})$ selection and used as target cells in the CML tests described above. LH8-2, L-cells transformed with cosmid $H 8$ containing the $K^{b}$ gene (see ref, 4 ). TF, technical failure.

* Significant lysis. 
simple sequence DNA. In any event the presence of DNA sequences of $90 \% \mathrm{G}+\mathrm{C}$ is likely to enhance pairing of homologous sequences because $\mathrm{G}+\mathrm{C}$ duplexes are very stable (so that a shorter duplex is required for the minimal stability to hold a newly nucleated hybrid) and as essentially only two bases are involved the complexity of this DNA is very low and hence the probability of finding a 'homologous' sequence is high.

These arguments do not explain why the frequency of a number of different alleles of the wild mouse or human popula-

Received 28 October 1982; accepted 14 January 1983.

1. Steinmetz, M. et al. Cell 25, 683-692 (1981).

2. Margulies, D. H., Evans, G. A., Flaherty, L. \& Seidman, J. G. Nature 295, 168-170 (1982),

3. Steinmetz, M., Winoto, A., Minard, K. \& Hood, L. Cell 28, 489-498 (1982).

4. Mellor, A. L. et al. Nature 294, 529-534 (1982).

5. Klein, J. in Biology of the Mouse Histocompatibility-2 Complex, 192-230 (Springer, New York, 1975).

6. Slightom, J. L., Blechl, A. E. \& Smithies, O. Cell 21, 627-638 (1980).

7. Flavell, R. A. et al. Proc. Gth int. Congr. Hum. Genet., Israel (Liss, New York, 1981).

8. LaLanne, J. L. et al. Nucleic Acids Res. 10, 1039-1049 (1982).

9. Evana, G. A., Margulies, D. H., Camerini-Otero, R. D., Ozato, K. \& Seidman, J. G. Proc. matn. Acad. Sci. U.S.A. 79, 1994-1998 (1982). tion $\boldsymbol{H}-2$ or HLA is high compared with other gene systems. This is best explained by invoking a selective advantage to the individual with a new allele, for example, in cytotoxic T-cell mediated resistance to viral infection but is beyond the scope of this article.

L.G. was the recipient of a fellowship from the Helen Hay Whitney Foundation. This work was supported by the British MRC and Biogen, NV. We thank Madlyn Nathanson for the preparation of this manuscript.

\footnotetext{
10. Weiss, E. H. et al. EMBO J. (in the press).
11. Grosveld, F. G., Dahl, M. H. H., de Boer, E. \& Flavell, R. A. Gene 13, 227-237 (1981).

11. Grosveld, F. G. et al. Nucleic Acids Res. 10, 6715-6732 (1982)

13. Nairn, R., Yamaga, K. \& Nathenson, S. G. A. Rev. Genet. 14, 241-277 (1980),

13. Nairn, R., Yamaga, K. \& Nathenson,
14. Golden, L. et al. (in preparation).

14. Golden, L. et al. (in preparation).
15. Nairn, R., Nathenson, S. G. \& Coligan, J. E. Eur. J. Immun. 10, 495-503 (1980)

16. Moore, K. W., Sher, B. T., Sun, H. Y., Eakle, K. A. \& Hood, L. Science 215, 679-682 (1982).

17. Reyes, A. A., Schold, M., Hakura, K. \& Wallace, R. B. Immunogenetics 16, 1-9 (1982).

18. Bailey, D. W. \& Kohn, H. J. Genet. Res. Camb. 6, 330-340 (1965)

19. Moschonas, N., de Boer, E. \& Flavell, R. A. Nucleic Acids Res. 10, $2109-2120$ (1982).

20. Moschonas, N. et al. Nucleic Acids Res. 9, 4391-4401 (1981).

21. Wigler, M. et al. Proc. natn. Acad. Sci. U.S.A. 76, 1373-1376 (1979).
}

\title{
Location and primary structure of a major antigenic site for poliovirus neutralization
}

\author{
P. D. Minor, G. C. Schild, J. Bootman, D. M. A. Evans, M. Ferguson, \\ P. Reeve \& M. Spitz
}

National Institute for Biological Standards and Control, Holly Hill, London NW3 6RB, UK

\section{G. Stanway, A. J. Cann, R. Hauptmann, L. D. Clarke, R. C. Mountford \& J. W. Almond}

University of Leicester, University Road, Leicester LE1 7RH, UK

\begin{abstract}
We have determined a major antigenic site for virus neutralization on the capsid protein VP1 of poliovirus type 3. Antigenic mutant viruses selected for resistance to individual monoclonal antibodies had point mutations concentrated in a region 277-294 bases downstream from the start of the region of viral RNA coding for VP1. These findings provide the basis for an improved understanding of the molecular basis of virus neutralization.
\end{abstract}

THE causative agents of poliomyelitis ${ }^{1}$, classified into poliovirus types 1,2 and 3 on the basis of their serological characteristics, are members of the family Picornaviridae, a large group of viruses of considerable importance in human and veterinary disease. They are small viruses ${ }^{2}$ possessing single-stranded, messenger-sense RNA genomes of about $2.6 \times 10^{6}$ molecular weight ( $\sim 7.5$ kilobases) enclosed in a protein capsid composed of 60 copies each of four virus-encoded polypeptides VP1, VP2, VP3 and VP4, ranging in molecular weight from 4,000 to 30,000 . Specific antibodies capable of neutralizing virus infectivity are considered to be the major mechanism of protection against infection and disease. However, information on the nature of the antigenic structures involved in poliovirus neutralization is incomplete and the precise mechanisms by which virus is neutralized by antibody remain uncertain.

Here we describe the analysis of the antigenic structure of poliovirus type 3 by the isolation and characterization of mutant viruses resistant to neutralizing monoclonal antibodies. A major antigenic site involved in the neutralization of type 3 poliovirus has been identified in this way.

\section{Isolation of mutant viruses}

Four preparations of well-characterized, closely related type 3 polioviruses were used in the study. P3-Leon-USA-1947, the virulent precursor of the live attenuated Sabin type 3 vaccine strain $^{3}$ was obtained from Dr A. Sabin. Most of the work described here concerned a plaque-purified isolate derived from this preparation, designated Leon 970 . The live attenuated Sabin type 3 vaccine strain (WHO vaccine reference preparation) and a plaque-purified derivative of it, designated Sabin 411 , were also used. These viruses are also the subject of cloning and sequencing studies in our laboratories.

The preparation of rat and mouse hybridoma cell lines secreting monoclonal antibodies to poliovirus type 3 is described elsewhere (refs 4, 5 and M.F., in preparation).

A total of 103 monoclonal antibody-resistant plaques were picked in independent selections from Leon 970 using six different monoclonal antibodies and the virus eluted from each plaque was subjected to a second cycle of selection. Of the 103 primary plaques, 101 were bona fide mutants as their titres were unaffected by the presence of the selecting antibody in the second cycle of selection.

The frequencies with which mutants were isolated from the parental virus populations are expressed in Table 1 as the number of parental virus plaques per mutant for P3-LeonUSA-1947, Leon 970, Sabin type 3 vaccine, and Sabin 411. Plaque purification of parental virus did not affect the frequency of antigenic mutants obtained for either P3-Leon-USA-1947 or the Sabin type 3 vaccine strain. This agrees with present views on the nature of the virus RNA genome which is regarded as highly mutable, rapidly achieving an equilibrium level of heterogeneity on passage ${ }^{6}$.

Antigenic mutants could be isolated from P3-Leon-USA1947 at 10 times the frequency with which they were obtained 